\title{
LASER MICROBEAM SURGERY: ULTRASTRUCTURAL CHANGES ASSOCIATED WITH NEURITE TRANSECTION IN CULTURE ${ }^{1}$
}

\author{
GUENTER W. GROSS, ${ }^{2}$ JEN H. LUCAS, AND M. LOUISE HIGGINS
}

Department of Biology, The Texas Woman's University, Denton, Texas 76204

Received February 22, 1983; Revised April 28, 1983; Accepted May 6, 1983

\begin{abstract}
The exposure of neuronal and glial cell processes to a large number (up to 300) of 12-nsec laser pulses at a wavelength of $337 \mathrm{~nm}$ and energy densities below the threshold for nonlinear absorption results in a gradual, gentle process transection in the laser focus. Within 10 to $20 \mathrm{sec}$ after cessation of firing, the process pinches in the target area. During this time, mitochondria become swollen and bleached, the plasma membrane develops an obvious tautness, microtubules disappear, and organelles accumulate to either side of the process constriction. Depending on the irradiation parameters, a local pinching may proceed to a transection in about $30 \mathrm{sec}$ or it may reverse to yield a normalappearing process in approximately $5 \mathrm{~min}$. Severe process pinching is accompanied by a sudden depolarization that may last for 2 to $5 \mathrm{~min}$ and is usually followed by a repolarization to the original resting potential even if the process has transected. Spiral retraction of cut processes and cytoplasmic spillage observed after mechanical transections are not seen with this laser method. Process stretching is minimized or eliminated. Extensive vacuolization often associated with mechanical transections does not develop unless substrate involvement in the form of shock waves is apparent. For the performance of cell surgery in culture, this method appears to offer a reliable approach to morphological alteration of single cells and to the tailoring of two-dimensional neuronal networks. It should also allow more quantitative and better-controlled studies of axonotmesis, degeneration, and regeneration on the single cell level, and it may be used as a probe for the investigation of cytoskeletal dynamics. A mechanism describing the cytoskeletal changes associated with laserinduced cell process transection is proposed.
\end{abstract}

A variety of studies in neurobiology require the creation of precise lesions to permit a determination of the functional role played by deleted cells or their components, and to investigate the regenerative capacities and reactions to trauma of neuronal and glial units following process amputation. Three primary approaches have been used to perform localized manipulations in situ as well as in culture: (1) mechanical lesions produced with various types of microknives (Chambers and Fell, 1931; Levi and Meyer, 1945; Mire et al., 1970; Shaw and Bray,

\footnotetext{
${ }^{1}$ We thank Dr. Michael Rudick, Department of Biology, The Texas Woman's University, and Dr. Joel Kirkpatrick, Department of Pathology, Baylor College of Medicine, for the critical reading of the manuscript. We also thank Dr. W. Meier-Ruge of Sandoz A.G. Basel, Switzerland for his generous support in the early phase of these investigations and acknowledge, with great appreciation, the donation by the Sandoz Corporation of the UV laser microbeam system used in these studies. Finally, we thank the National Institute of Neurological and Communicative Disorders and Stroke for support under Grant NS15167.

${ }^{2}$ To whom correspondence should be addressed.
}

1977; Bird, 1978; Sole, 1980), (2) the selective illumination and concomitant destruction of neurons or neurites after injection with fluorescent dyes (Miller and Silverston, 1979; Cohan et al., 1982), and (3) cell elimination via enzyme injection (Parnas and Bowling, 1977; Bowling et al., 1978). Although these methods have provided valuable data, their potential is limited. The techniques are not sufficiently precise for many applications. Secondary effects such as neurite stretching during transection, photochemical reactions, and injection trauma often limit the conclusions that can be drawn. Nevertheless, with increased interest in the correlation between electrical function and morphology (Rall and Rinzel, 1973; Butz and Cowan, 1974; Horwitz, 1981a, b) as well as in the simultaneous monitoring of spike activity from ordered networks in culture (Gross, 1979; Gross et al., 1982; Gross and Lucas, 1982), the need for surgical intervention on the cellular level has grown. Therefore, a fourth method, which effects the desired lesions by means of laser microbeams focused through a microscope, has attracted increasing interest. 
The laser method offers several important advantages. It permits high power microscopic observation during surgical manipulations. The surgery can be performed in closed chambers under sterile conditions. Lesions less than $1 \mu \mathrm{m}$ in diameter can be produced without disturbing neighboring structures. Much complex mechanical micromanipulation is obviated. Finally, the secondary effects mentioned above are minimized if not entirely eliminated.

Observations in two laboratories have already established that neurite transection can be performed with single laser pulses at a wavelength of $337 \mathrm{~nm}$ and pulse duration of $12 \mathrm{nsec}$ (Rieske et al., 1977; Rieske and Kreutzberg, 1978; Gross et al., 1979; Higgins et al., 1980). However, systematic studies of cell reactions to laserinduced process amputation have not yet been published. At the present time, it is not known whether laser cell surgery produces long-range physiological or morphological changes beyond those directly associated with the desired geometrical alterations.

We have previously reported two techniques of laser cell surgery utilizing near-UV irradiation $(337 \mathrm{~nm})$ : direct, single shot cytoplasmic lesions at high energy densities, and indirect, single shot transections via minute shock waves resulting from substrate vaporization below the target process (Higgins et al., 1980). The former is achieved at energy densities exceeding $3 \mu \mathrm{J} / \mu \mathrm{m}^{2}$ and probably represents nonlinear, multiphoton absorption in cytoplasm (Hillenkamp, 1980). This technique can only be used on quartz and some glass surfaces to prevent substrate involvement. The second technique is designed purposely to utilize substrate vaporization to effect cytoplasmic lesions. Although both neuronal and neuroblastoma cells have been observed following laser surgery for periods up to 3 weeks with no obvious deleterious effects, recent transmission electron microscopic (TEM) observations of cells fixed within $10 \mathrm{~min}$ after process transection have revealed cytoplasmic disruption outside the laser impact area (Lucas et al., 1982). Concern over possible physiological impairment following cell surgery with these techniques has stimulated the development of an alternative approach.

In this paper we introduce a third laser technique which produces a minimum of cytoplasmic damage outside the target area. Transection is achieved at low energy densities as a result of cumulative absorption (up to 300 shots) of UV irradiation within the laser focus rather than by single shot vaporization of cytoplasm or substrate materials. Using transmission electron microscopy, we compare the intracellular damage created by this new technique with that generated by the single shot, shock wave techniques. This study demonstrates that the multiple shot approach is superior to the other two laser techniques as well as to mechanical methods of transection. It achieves a highly localized collapse of the cytoskeleton reflected by a slow, gentle pinching of neurites and subsequent process transection. This occurs over a 10 - to 40 -sec time span, thus permitting investigation of structural changes during and after process transection. The significance of this technique is therefore not limited to cell surgery; it also represents an interesting new probe of the cytoskeletal dynamics associated with reactions to trauma.

\section{Materials and Methods}

Cell culture. Spinal cords from 13- and 14-day mouse embryos were cultured according to the method of Ransom et al., (1977) and modified as previously reported (Gross et al., 1982; Gross and Lucas, 1982). NB41A3 mouse neuroblastoma cells were purchased from the American Type Culture Collection, Rockville, MD, and cultured as previously described (Higgins et al., 1980).

Laser cell surgery. Laser cell surgery was performed with a pulsed nitrogen laser operating at $337 \mathrm{~nm}$ and maximum output of $14 \mathrm{~kW}$. The laser microbeam system and its operation are described by Higgins et al. (1980). Single cell experiments were performed with a $\times 32$ quartz phase contrast objective (Zeiss Ultrafluar) resulting in a minimum focus diameter of $2.3 \mu \mathrm{m}$.

Each laser pulse was monitored with a UV-sensitive diode before the beam entered the microscope (see Higgins et al., 1980). For additional calibration, the energy leaving the objective was measured before each experiment with a detection system affixed to the microscope stage (Phase-R Inc., New Durham, NH).

Experiments were conducted in Falcon or Lux culture dishes with perforated caps through which the objective was introduced into the culture medium. The temperature of the medium was maintained between 35 and $37^{\circ} \mathrm{C}$ by means of DC-heated copper plate below the dish. Because the Zeiss Ultrafluar objectives are heat sensitive and may be damaged at temperatures above $30^{\circ} \mathrm{C}$, a plastic sleeve with a matched quartz coverglass window was placed over the objective before immersion in medium. The $\mathrm{pH}$ of the culture medium was maintained near 7.4 by a slow stream $(20 \mathrm{ml} / \mathrm{min})$ of $5 \% \mathrm{CO}_{2}$ in humidified air. All manipulations and observations under the microscope were conducted with a green filter at normal light intensities required for phase contrast microscopy.

Surgical manipulations were performed on neuronal and non-neuronal cells from dissociated spinal cord cultures (12 to 45 days in culture). Laser firing frequencies of 4,20 , and $60 \mathrm{~Hz}$ were employed. Firing intervals ranged from $1 \mathrm{sec}$ to that at which $100 \%$ transection was achieved. Post-lasing effects determined at $30 \mathrm{sec}$ were categorized as follows: $\mathrm{N}$, no visible effect; $\mathrm{P}$, pinching or partial transection with thinning of the process in the target area; C, cytoplasmic transection (complete cytoplasmic interruption although thin strands still connect proximal and distal portions of the target process); and $\mathrm{T}$, total transection with no remaining interconnections. Observation of laser irradiation effects for longer periods indicated that partial transections (i.e., process pinching) were generally followed by a recovery to pre-lasing dimensions whereas cytoplasmic transection usually became total. Consequently, the "C" and "T" categories were grouped together when calculating the percentage of transection.

The percentage of transection achieved $(\mathrm{C}+\mathrm{T})$ during an experiment at each combination of firing frequency, 


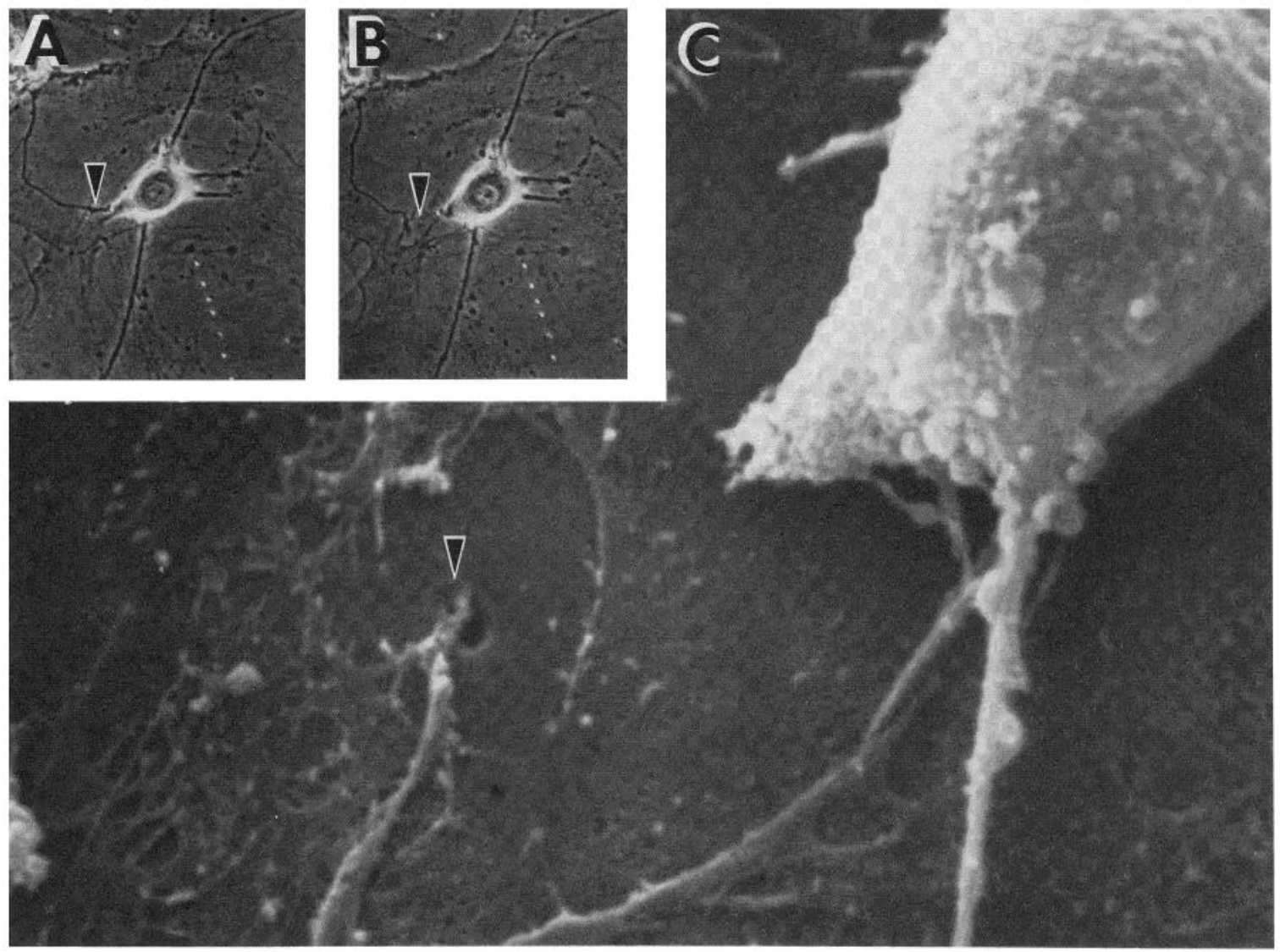

Figure 1. Single shot process transection of mouse brain neurite via substrate shock wave (indirect transection). Energy density: $1.2 \mu \mathrm{J} / \mu \mathrm{m}^{2} . A$ and $B$, Neuron before and after surgery at arrowhead. Magnification $\times 400$. Diagonal laser shot patterns are used for cell identification. $C$, Scanning electron microscopy of crater (arrowhead) and cell. Magnification $\times 2800$. Substrate: Lux Thermanox, damage threshold $0.2 \mu \mathrm{J} / \mu \mathrm{m}^{2}$; fixation: $2 \mathrm{~min}$ after shot.

energy density, and firing interval was based on at least five transection attempts. Points presented graphically in this paper represent averages of at least five percentages (i.e., a minimum of 25 cell process irradiations).

Electron microscopy. The methods for scanning electron microscopy studies and identification of the cells have been described previously (Higgins et al., 1980). For TEM, cells were grown on Permanox culture dishes, fixed by adding phosphate-buffered $3 \%$ glutaraldehyde $(\mathrm{pH}$ 7.4) to the culture medium to give a final concentration of $1 \%$ glutaraldehyde. After $5 \mathrm{~min}$ the medium plus fixative were removed, buffered glutaraldehyde was added, and fixation continued for $1 \mathrm{hr}$ at room temperature. The cells were postfixed in phosphate-buffered $1 \%$ osmium tetroxide ( $\mathrm{pH} \mathrm{7.4)}$ for $1 \mathrm{hr}$, dehydrated through an ethanol series followed by propylene oxide, and embedded in a mixture of Epon and Araldite. Following polymerizeration the sides of the culture dish were cut off and a rectangle with the surgically manipulated cell in the center was drawn on top of the Epon with a needle. The remainder of the dish was removed, and the Epon disk containing the cell was cut out and glued to a clear plastic rod. Thin sections positioned on Formvar-coated grids and stained with uranyl acetate and lead citrate were examined with a Siemens 101 electron microscope.

\section{Results}

A typical substrate shock wave transection is shown in Figure 1. The scanning electron micrograph clearly reveals the crater in the substrate, the disruption of a flat fibrocyte or epithelial cell, and the retraction of the proximal process. Cytoplasmic spillage is almost never associated with such transections. Despite the shock wave from vaporized substrate material, the morphological damage is localized. The pathological limits of this type of surgery are a function of culture conditions, cell type, process diameter, magnitude of the shock wave, and distance of lesion from the cell body. However, more data are necessary before a precise description of cell reactions to shock wave surgery can be given. A direct cytoplasmic transection of processes on plastic substrates is not possible with single laser shots because the higher energy densities required for cytoplasmic vaporization would affect this type of substrate which displays damage thresholds at lower energy densities. The resulting substrate shock wave could be severe and create excessive damage that may cause process stretching or damage to neighboring structures.

The long-term reactions of mammalian CNS cells to process amputation are typified by Figure 2. A partial 

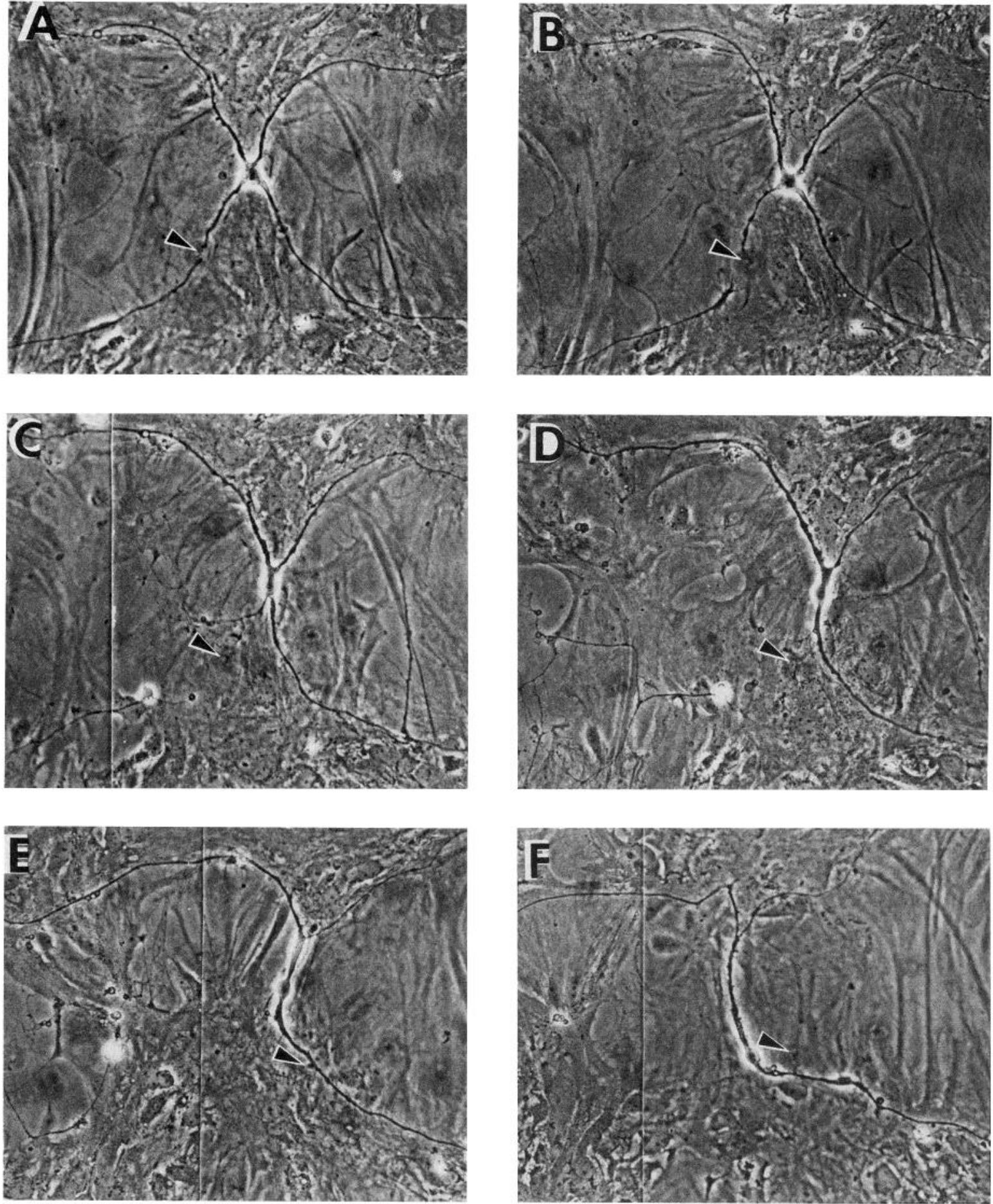

Figure 2. Long-term survival of mouse CNS cell (probably oligodendrocyte) after process amputation via substrate shock wave method. Magnification $\times 150$. Substrate: Falcon polystyrene, damage threshold $2 \mu \mathrm{J} / \mu \mathrm{m}^{2} ;$ energy density: $2.5 \mu \mathrm{J} / \mu \mathrm{m}^{2}$. $A$, Appearance of cell $1 \mathrm{hr}$ after surgery (at arrowhead) showing a process retraction of approximately $10 \mu \mathrm{m}$ and a faint circular area produced by substrate reaction to the laser pulse. $B$, The same cell $5 \mathrm{hrs}$ after surgery. The proximal process shows beading but no further retraction while the distal process has retreated $25 \mu \mathrm{m}$. The single arrowhead identifies the location of the laser shot. $C$, The same cell 1 day after the amputation, showing further atrophy. $D, E$, and $F$, Two, 4 , and 7 days, respectively, after process amputation. Changes in the shape of the perikaryon are at least partially the result of culture conditions.

process retraction from the $2-\mu \mathrm{m}$ diameter target region (at arrow) in the first hour is followed by process beading, further retraction of the proximal segment, and eventual resorption on day 2 after transection. The distal segment atrophies and finally disappears between 4 and 7 days. Substantial morphological distortions are evident; how- ever, the constant shifting of the underlying fibrocyte carpet and changing culture conditions produced similar effects in control cells. No clear association of such changes with the laser surgery can yet be demonstrated. Furthermore, numerous observations of cells with light microscopy after surgery have shown cell survival with 

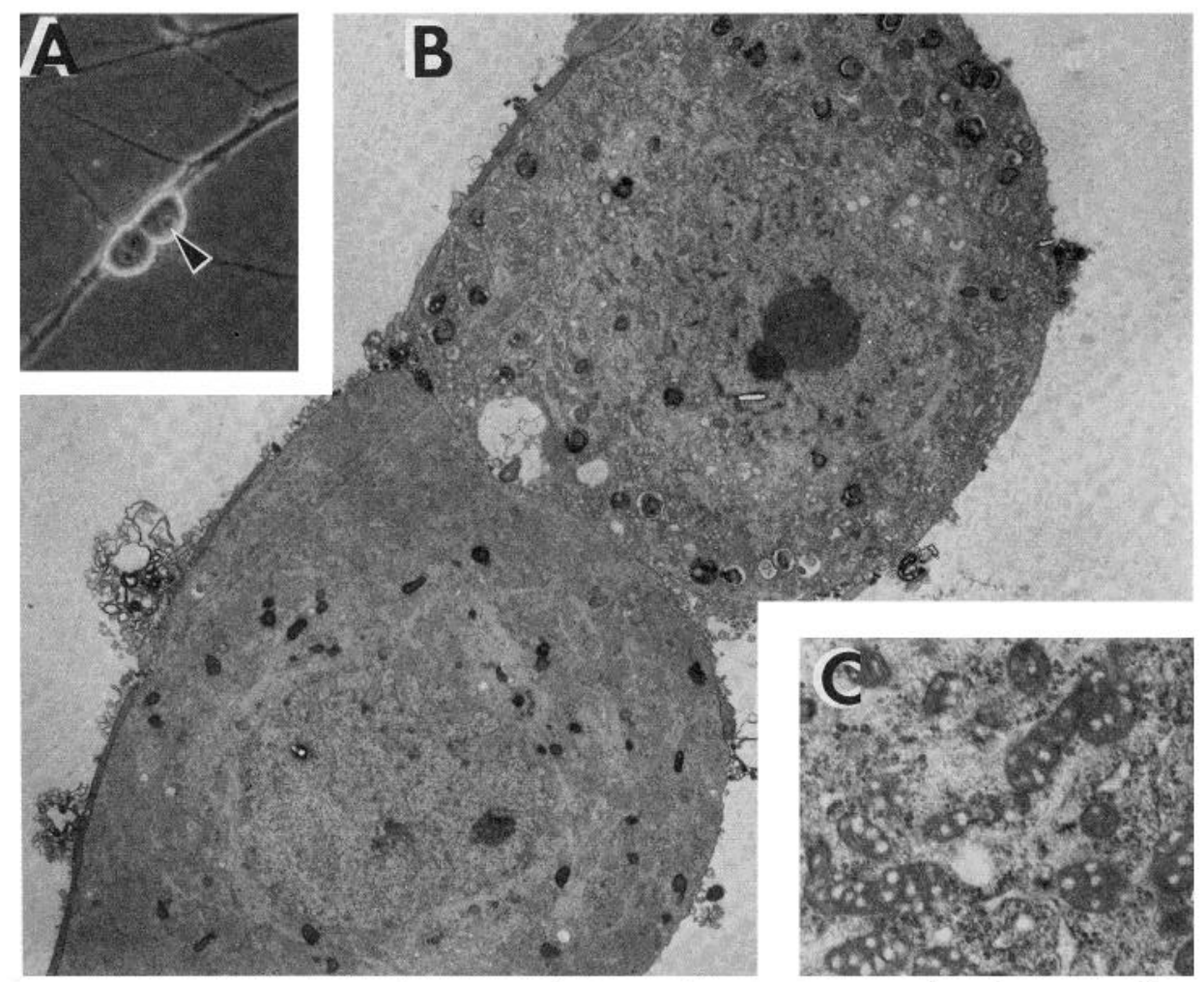

Figure 3. Cytoplasmic and mitochondrial vacuolization in mouse dorsal root ganglion cell body $4 \mathrm{~min}$ after laser irradiation. $A$, The cell (at arrowhead) was subjected to 25 shots at $2.5 \mu \mathrm{J} / \mu \mathrm{m}^{2}$ focused into the substrate below the nucleus creating a large substrate shock wave. $B$, Electron micrograph showing cytoplasmic disruption in an irradiated cell. The adjacent cell reveals no similar deterioration despite close membrane contact. Magnification $\times 3,800$. C , High magnification of mitochondrial damage in irradiated cell. Magnification $\times 13,600$. Substrate: Lux Permanox, damage threshold 2 $\mu \mathrm{J} / \mu \mathrm{m}^{2}$.

no obvious morphological deterioration (Higgins et al., 1980).

Despite these encouraging results, TEM has provided evidence that the shock wave method of transection does produce damage beyond the immediate target area. This is shown in Figure 3, where the cytoplasm of the targeted cell body reveals numerous small vacuoles, especially in mitochondria. The neighboring cell, which is in membrane contact with the affected cell, shows no such reaction. This degree of cytoplasmic disruption generally leads to cell death and is indeed a very effective method for specific cell deletion in culture. However, Figure 3 also demonstrates damage spread since a shock wave lesion was generated under the nucleus of the targeted cell and cytoplasmic disruption appeared $15 \mu \mathrm{m}$ from the target in $4 \mathrm{~min}$, halting abruptly at the membrane. As some regions of the normal-appearing neighbor were as far from the laser focus as damaged cytoplasm of the irradiated cell, scattered radiation does not appear to be responsible for this effect. A diffusible and/or transported factor is most likely to cause this extensive cytoplasmic disruption.

Further evidence for damage spread can be seen in Figure 4 which shows the cytoplasmic reactions of a mouse brain neuron to a substrate shock wave transection. A $3.5-\mu \mathrm{m}$-wide dendrite was amputated $20 \mu \mathrm{m}$ from the nucleus and only $8 \mu \mathrm{m}$ from the edge of the cell body with a single laser pulse at an energy density of $2.5 \mu \mathrm{J} /$ $\mu \mathrm{m}^{2}$. In the $4 \mathrm{~min}$ between the laser shot and fixation, extensive vacuolization has spread from the target region in the 2.3- $\mu \mathrm{m}$ diameter laser focus to the perinuclear area. The cytoplasmic disturbance spread at approximately $1 \mu \mathrm{m} / \mathrm{sec}$. The apical dendrite does not contain such vacuoles. A control cell shown here only in the light microscope inserts also displayed normal cytoplasm when viewed with electron microscopy.

Although efficient cell deletion necessitates a capability for inflicting lethal damage to the targeted cell, process transection must be accomplished with a minimum of damage. In such a case cell survival is vital and damage should ideally be confined to the laser focus. Therefore, the damage shown in Figures 3 and 4 is cause for concern as physiological impairment may result even if cells survive. Consequently, we have investigated a third technique of laser cell surgery which utilizes a high number of laser pulses at energy densities below those required for cytoplasmic cavitation and also below the damage thresholds of most substrate materials. ${ }^{3}$

The cumulative nature of cytoplasmic reactions to this

\footnotetext{
${ }^{3}$ Energy densities for damage thresholds of various substrate materials were tabulated in Higgins et al. (1980). Although the damage threshold hierarchy of the table is unaltered, values for energy densities presented in this paper are more accurate.
} 

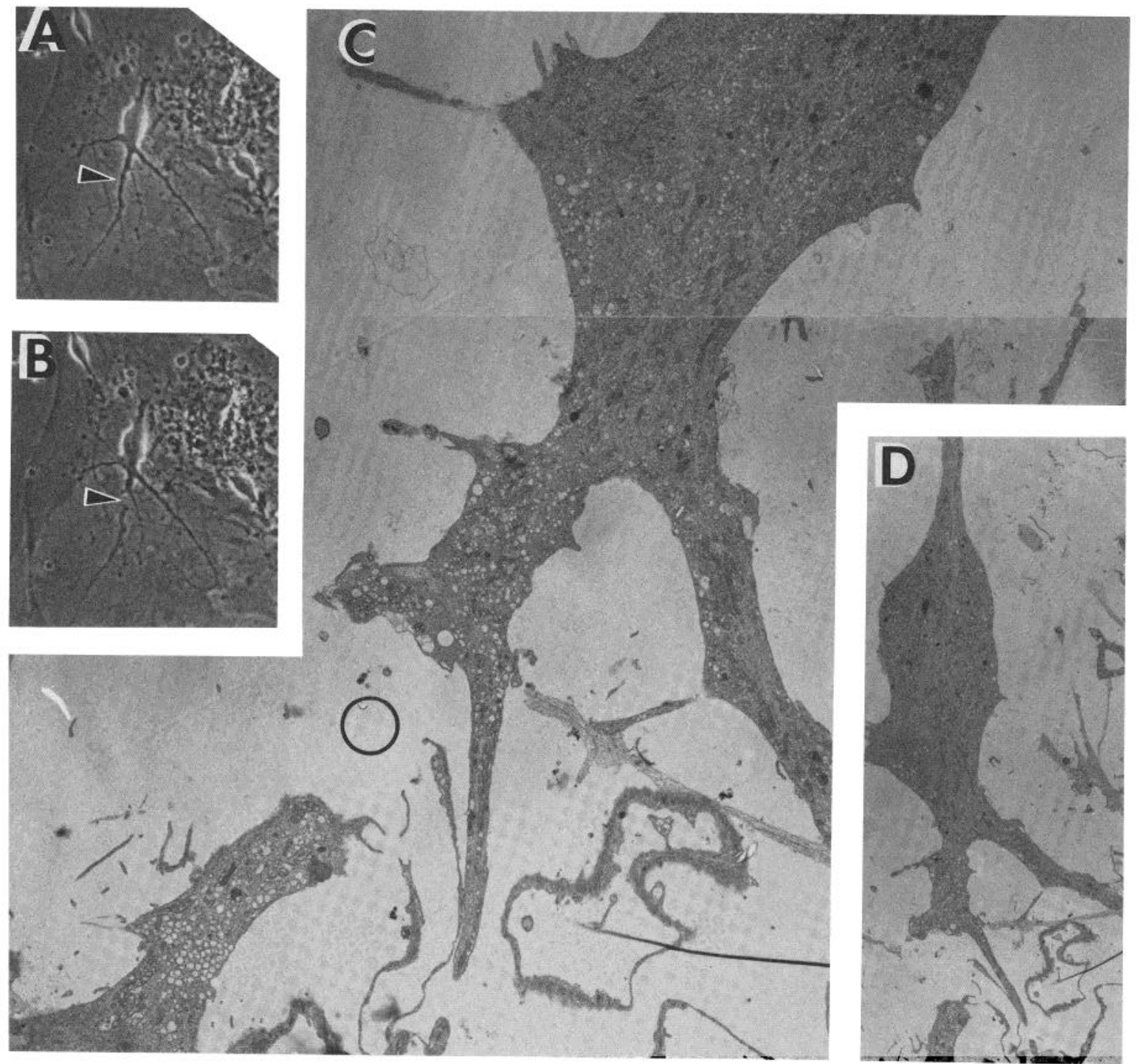

Figure 4. Single shot, substrate shock wave transection of mouse brain neuron near the cell body. Energy density: $2.5 \mu \mathrm{J} / \mu \mathrm{m}^{2}$; substrate: Lux Permanox; fixation: $4 \mathrm{~min}$ after shot. $A$ and $B$, Light micrographs of neuron before and after process amputation (at arrowhead). Magnification $\times 200$. C , High magnification $(\times 3800)$ of target area and lower cell body showing lesion and spreading cytoplasmic disruption. Location and size of laser focus are represented by the circle. D, Micrograph of target neuron showing that vacuolization has spread to the perinuclear area but is not present in the apical dendrite. Magnification $\times 1200$.

lasing technique is depicted in Figure 5, which represents the typical stages of multiple shot transection as seen with the light microscope. Depending on energy density and number of shots, neuronal and glial cell processes undergo a gradual pinching during the laser firing which leads to a cytoplasmic transection if laser irradiation is continued. At this point (stage C in Fig. 5) a thin strand generally interconnects the proximal and distal segments. Total separation of these segments usually follows. This phenomenon seems to depend on several parameters such as process size, cell type, the presence or absence of a glial carpet, proximity to the cell body, and process tension, as well as on the irradiation parameters. For reasons of simplicity we have initially concentrated our efforts on cell processes of about the same diameter as the laser focus (i.e., $2.3 \mu \mathrm{m}$ ). It should be noted from the schematic drawing that a reversal of cytoplasmic pinching from stage B is usually observed.
Complete restoration of cytoplasmic continuity has also been seen after stage $\mathrm{C}$, albeit much less frequently.

Process pinching followed either by transection or recovery are demonstrated in Figure 6 . Two similar processes of the same mouse CNS glia cell were irradiated with 120 and 60 shots, respectively, at the same energy density and firing frequency. In the former case a cytoplasmic transection at $30 \mathrm{sec}$ was followed by a total separation of the process at $50 \mathrm{sec}$. In the latter case, in which the number of shots was reduced by $50 \%$, a pronounced pinching of the target area was followed by a recovery within $6 \mathrm{~min}$. These data demonstrate the slow and predictable nature of the transection sequence and show that the experimenter has considerable control during irradiation. Also, the cell's continued ability to recover from a partial transection despite amputation of a major process $8 \mathrm{~min}$ earlier is significant.

The minimal damage resulting from the multishot, low 


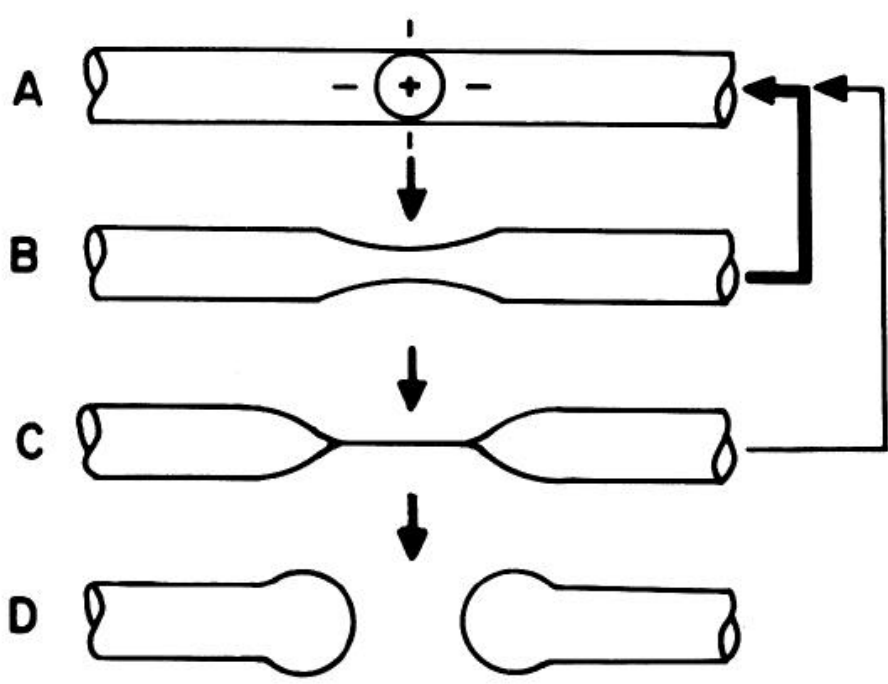

Figure 5. Schematic diagram representing the sequence of morphological changes which occur during process transection using the multiple shot, low energy method of laser cell surgery. $A$, Process prior to irradiation. The circle represents the area of UV laser focus. $B$, Partial transection with pinching of process in the area of laser focus. $C$, Cytoplasmic transection energy density method is revealed by electron microscopy in Figure 7. The application of 300 laser pulses at 100 $\mathrm{Hz}$ for $3 \mathrm{sec}$ and at an energy density of $1 \mu \mathrm{J} / \mu \mathrm{m}^{2}$ resulted in a complete transection $15 \mathrm{sec}$ after the initiation of firing. Despite exposure to a cumulative energy density of $300 \mu \mathrm{J} / \mu \mathrm{m}^{2}$, the cytoplasm of the neuroblastoma cell does not show vacuolization or abnormal mitochondrial ultrastructure beyond the disruption caused by the actual lesion. Under optimal conditions, the cytoplasm of all regions of targeted cells retains a normal appearance for fixation times between 1 and $10 \mathrm{~min}$ after the irradiation. Although cells have not yet been analyzed with TEM beyond this time period, the differences between the shock wave technique (Figs. 3 and 4) and the multishot low energy density technique are obvious and represent a significant reduction of side effects resulting from laser cell surgery.

with only a thin thread connecting the proximal and distal segments. $D$, Total transection with no remaining interconnections. The arrow from $B$ to $C$ indicates that recovery from partial transection is a frequent occurrence whereas recovery from $C$ to $A$ is rare. Most cytoplasmic transections $(C)$ become total $(D)$ within minutes.
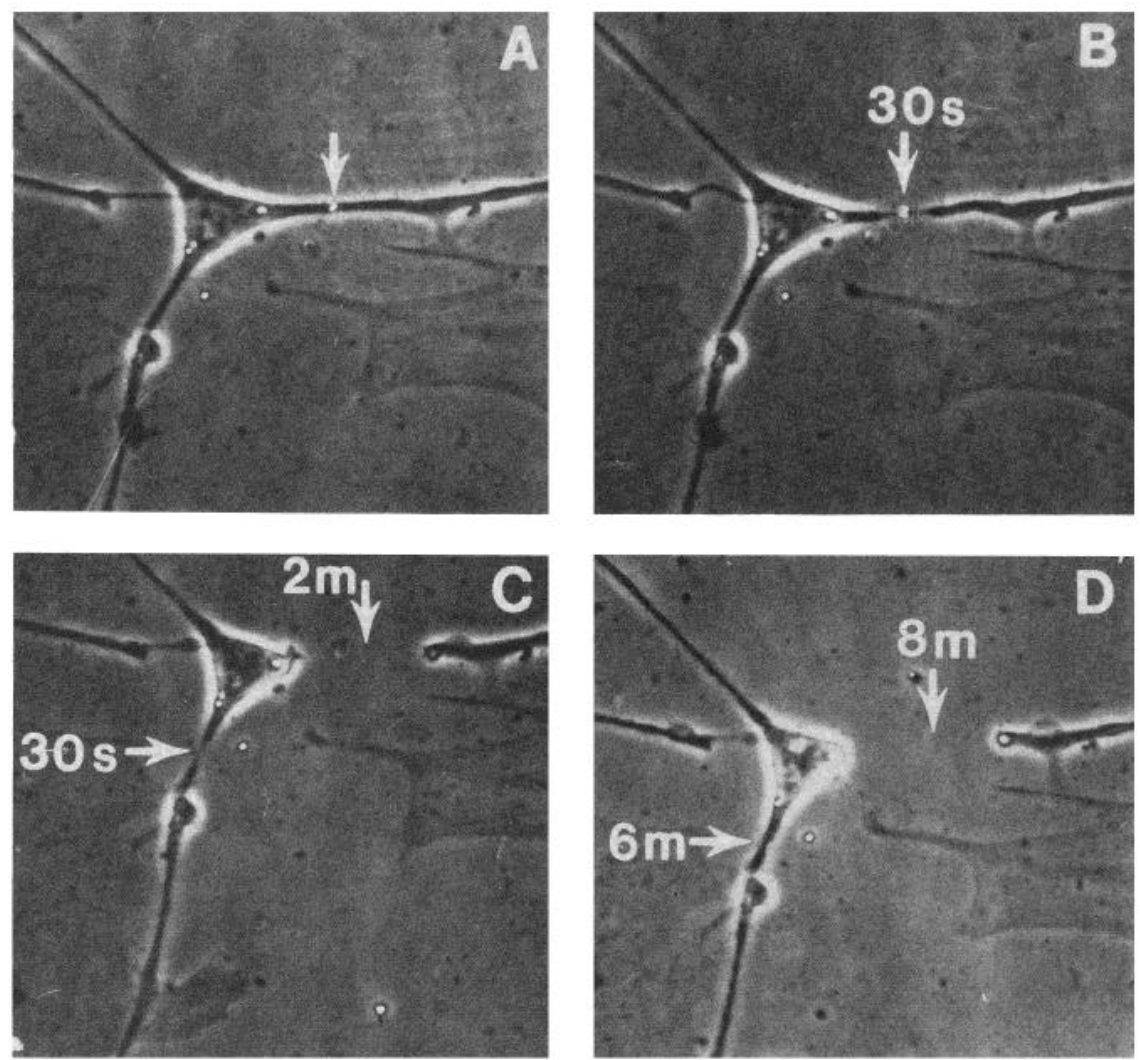

Figure 6. Effect of cumulative energy density (microjoules per square micrometer) on process transection. A tripolar glial cell was irradiated at two points with the same energy density and firing frequency but with 120 shots at one site (vertical arrow) and 60 shots at a second site (horizontal arrow). Process pinching followed by recovery was observed at the second site. $A$, Cell before irradiation with $\mathrm{HeNe}$ target laser at arrow. $B$, Cell $30 \mathrm{sec}$ after a $6-\mathrm{sec}, 20-\mathrm{Hz}$ exposure at $1.5 \mu \mathrm{J} / \mu \mathrm{m}^{2}$. C, Cell $30 \mathrm{sec}$ after a $3-\mathrm{sec}, 20-\mathrm{Hz}$ exposure at $1.5 \mu \mathrm{J} / \mu \mathrm{m}^{2} . D$, Cell 8 and $6 \mathrm{~min}$ after the first and second irradiation periods, respectively. Note that the pinched process at the second irradiation site has almost been restored to its original dimensions. Magnification $\times 330$. 

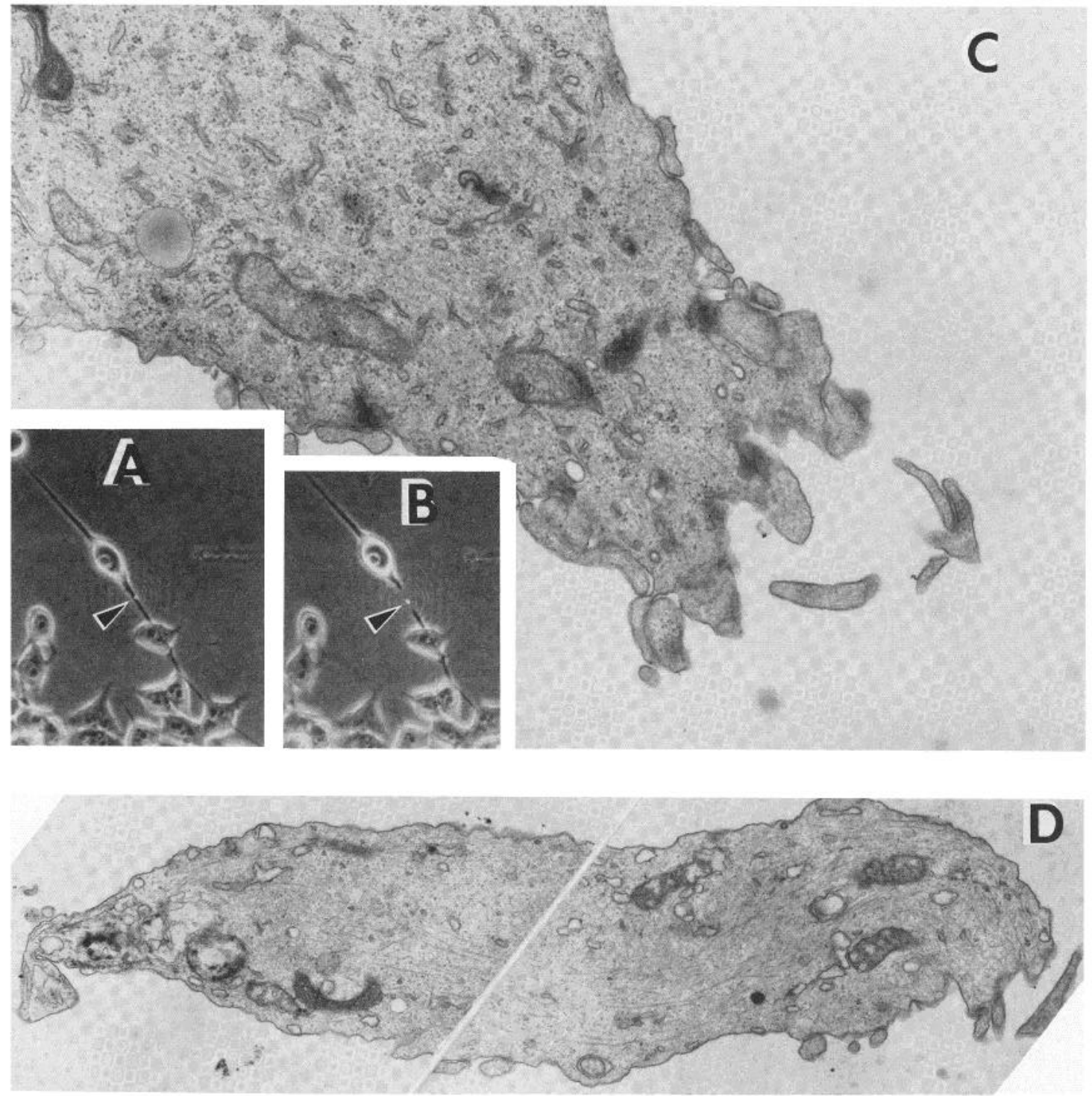

Figure 7. Local response of neuroblastoma cell to multiple shot laser process transection $\left(100 \mathrm{~Hz} ; 1.0 \mu \mathrm{J} / \mu \mathrm{m}^{2} ; 3 \mathrm{sec}\right) . A$, Cell prior to irradiation. The HeNe target beam is at the arrowhead. Magnification $\times 250$. B, Cell 30 sec after laser surgery. Magnification $\times 250$. $C$, Transmission electron micrograph of retracted proximal segment of transected process fixed 2 min after lasing. Note the absence of vacuolization and mitochondrial disruption. Magnification $\times 19,000$. D, Distal segment of transected process. Although there is some vacuole formation and mitochondrial disruption, damage diminishes with distance from the transection point (at left). Microtubules, which have disappeared at the cut end, are present but disorganized 4 to $5 \mu \mathrm{m}$ from the end. At $6 \mu \mathrm{m}$ from the cut end, microtubules display their normal longitudinal orientation. Magnification $\times 11,500$. Substrate: Lux Permanox.

Cell processes that are fixed during the initial phases of pinching in the laser focus show interesting cytoplasmic changes. Figure 8 is typical of ultrastructural disruption that has been seen in mouse neuroblastoma, CNS neurons, and CNS glia. These changes include a narrowing of the process diameter with a concomitant increased tautness of the plasma membrane. The cytoplasm appears more homogeneous with an apparent reduction of smooth endoplasmic reticulum and other organelles. Mitochondria within the target area are swollen and disrupted. Most significant is the complete disappearance of microtubules in the laser focus. Neurofilaments may also have been affected, although this is more difficult to determine. Mitochondria and other organelles are generally seen clustered to either side of the con- stricted region due to a cessation of transport or to cytoplasmic displacement associated with process constriction. We are presently of the opinion that "bleached" mitochondria outside the target area were probably in or close to the focus during laser firing but have been transported or squeezed out of this region at a time prior to fixation.

If similar cell processes are chosen for multishot transection and especially if the process diameters are selected to be approximately the size of the laser focus ( 2.3 $\mu \mathrm{m}$ with the Zeiss Ultrafluar $32 / 0.40$ objective), a quantitative description of transection can be obtained as a function of irradiation parameters. In Figure 9 we present data from mouse CNS cell processes in terms of transection probability as a function of number of shots at three 


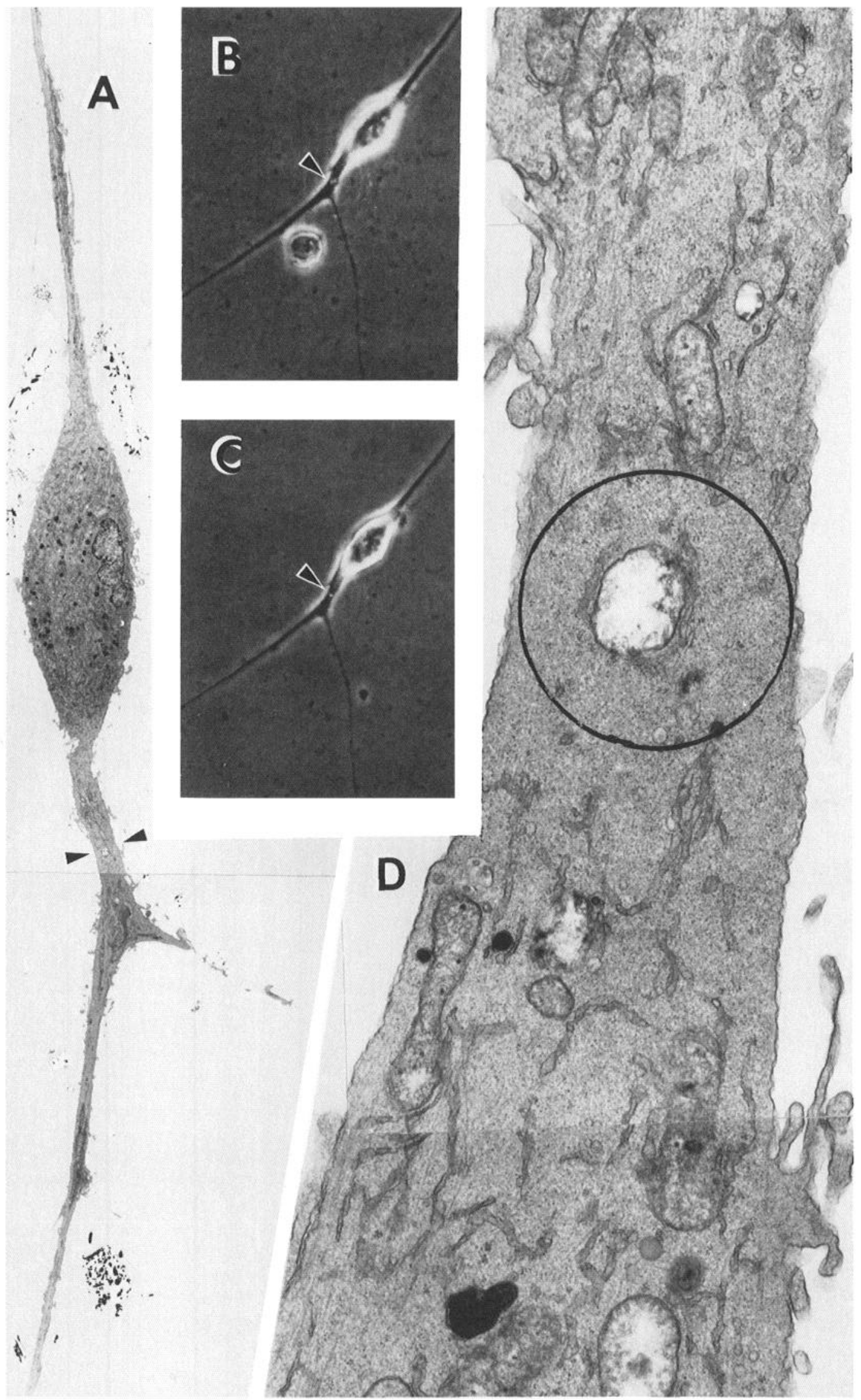

Figure 8. Early response of neuroblastoma cell to multiple shot UV laser cell surgery $\left(120 \mathrm{~Hz}, 0.4 \mu \mathrm{J} / \mu \mathrm{m}^{2}, 6 \mathrm{sec}\right)$. Substrate: Lux Permanox; fixation: $20 \mathrm{sec}$ after shot. $A$, Electron micrograph of entire cell with target area at arrowheads. Note absence of vacuolization. Magnification $\times 1,470$. B, Cell prior to laser irradiation. HeNe target beam is visible at the arrowhead. Magnification $\times 400$. $C$, Cell $15 \mathrm{sec}$ following irradiation. Note slight pinching. Magnification $\times 400 . D$, Electron micrograph of target area. In the vicinity of the laser focus (circle) the cytoplasm has a homogeneous appearance, the cell membrane appears taut, microtubules have disappeared, and organelles have accumulated to either side. Magnification $\times 19,000$. 

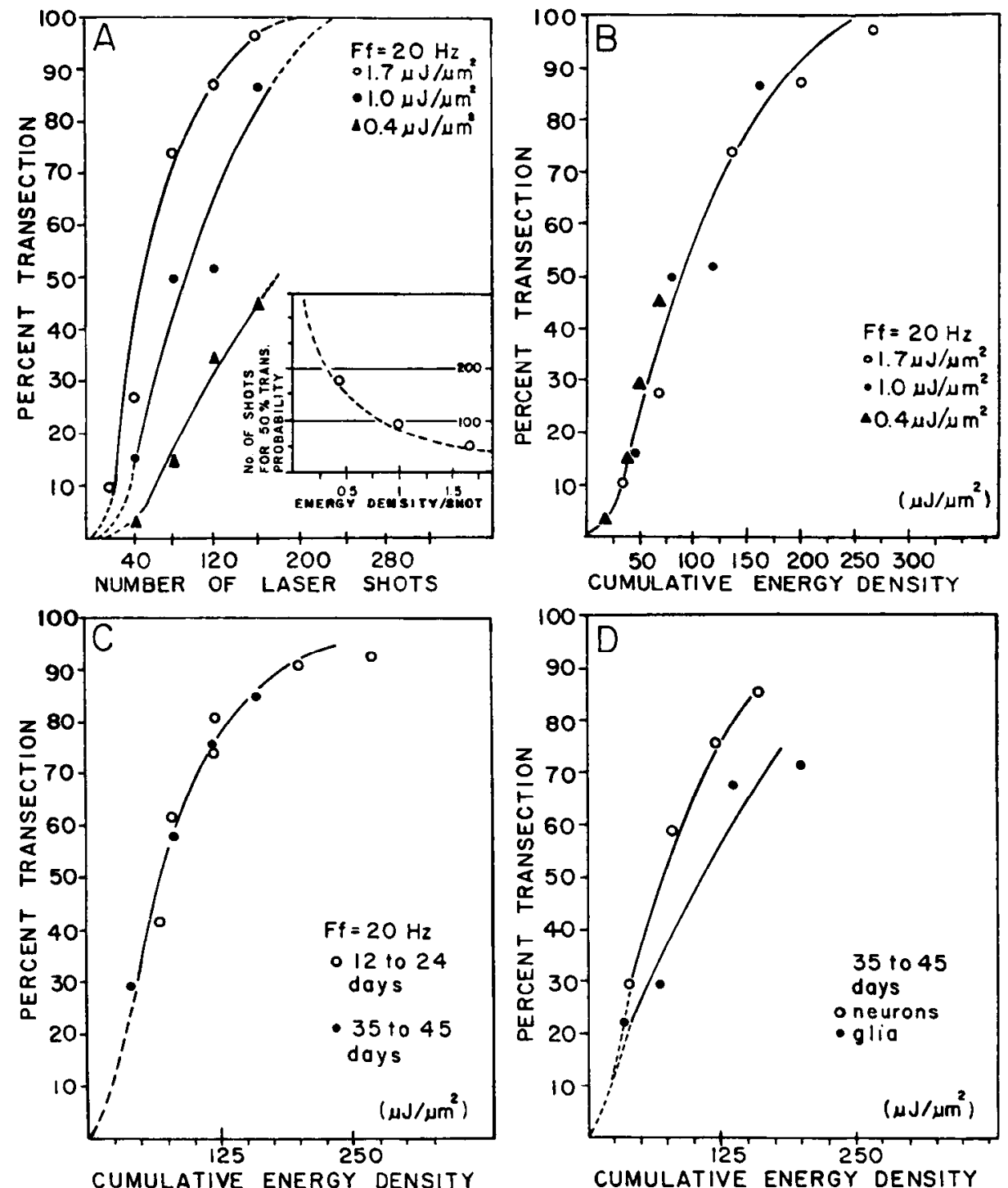

Figure 9. Transection probability in terms of percentage of transections obtained from a mixed population of mouse spinal cord cells at a laser firing frequency of $20 \mathrm{~Hz}$ as a function of number of laser shots $(A)$ and cumulative energy density ( $B$ to $D$ ). Each data point represents the average of five percentages, each obtained from 5 to 10 transection attempts. $A$, Three functions at energy densities of $1.7,1.0$, and $0.4 \mu \mathrm{J} /$ $\mu \mathrm{m}^{2}$, indicating that the number of shots required to obtain a specific transection efficiency is an inverse function of the energy density per shot (inset). $B$, The data from $A$ plotted as a function of cumulative energy density (i.e., the number of shots $\times$ $\mu \mathrm{J} / \mu \mathrm{m}^{2}$ ) converges to a single sigmoidal function. $C$, The age of the culture after plating does not affect the transection efficiency in the time periods indicated. $D$, Comparison of transection probability between neurons and glial cells. Non-neuronal cells appear to have a slightly lower susceptibility to transection.

different energy densities (Fig. $9 A$ ) and as a function of cumulative energy densities (Fig. $9, B$ to $D$ ). The latter parameter is merely the product of the number of shots times the energy density per shot. As expected, more laser pulses are required to achieve a specific transection probability at the lower energy densities (Fig. 9A). As a first approximation, it can be concluded that at $50 \%$ transection probability, the number of shots required is inversely proportional to the energy density per pulse (Fig. 9A, inset). This predicts that the cumulative energy density is a constant for a particular transection probability. This prediction is experimentally verified in Figure
$9 B$ in which the data of Figure $9 A$ converge to a single sigmoidal function.

At the present time it appears that culture age does not affect the transection probability between 12 and 45 days postseeding. (Fig. 9C). However, the data suggest that glia cells may be slightly more difficult to transect than neurons (Fig. 9D). It can also be concluded that process transection at energy densities below those that would result in single shot damage (i.e., below the damage threshold) depends primarily on the total number of photons arriving at the target area if the photons arrive in a short (seconds) period of time. At a constant firing 
frequency of $20 \mathrm{~Hz}$, the effect is the same whether a large number of photons per pulse is applied in a few pulses or a smaller number of photons per pulse is applied in many pulses as long as the photon density stays below the nonlinear absorption realm.

Experiments at higher laser firing frequencies (40 and $60 \mathrm{~Hz}$ ) have not shown an increase in transection probability. In fact, preliminary data indicate that the greatest transection efficiency may be achieved near $4 \mathrm{~Hz}$. This suggests a saturation of chromophores in the laser focus which must be replenished by diffusion or active transport processes.
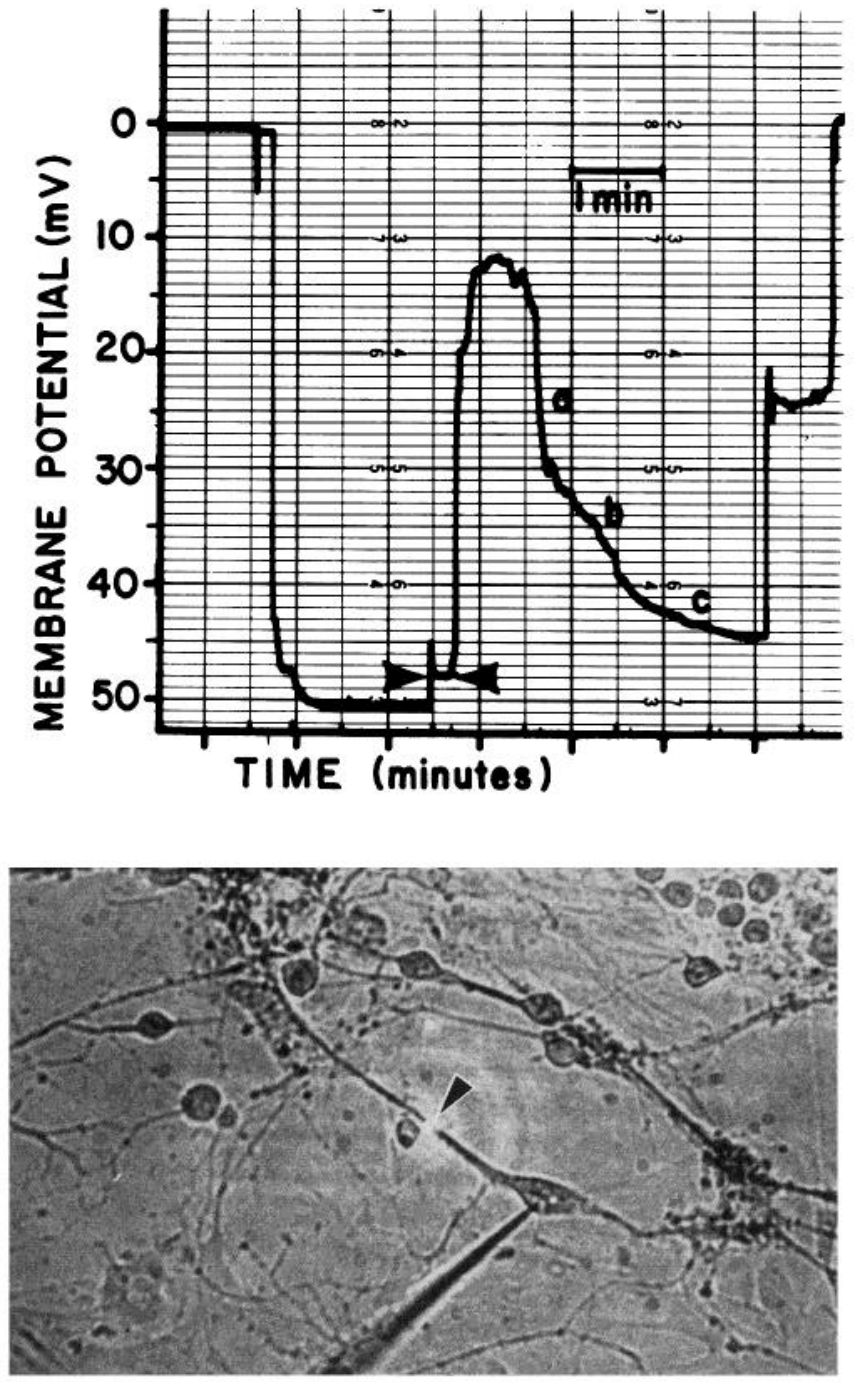

Figure 10. Changes in membrane potential of neuron in response to multiple shot transection. Top, The neurite was irradiated for $15 \mathrm{sec}$ (double arrowheads) at $20 \mathrm{~Hz}$. Energy density: $1.0 \mu \mathrm{J} / \mu \mathrm{m}^{2} /$ pulse. The cell depolarized to $-12 \mathrm{mV}$ and repolarized within $3 \mathrm{~min}$ after transection to $-45 \mathrm{mV}$. The different slopes of the recovery curve $(a, b$, and $c)$ have been observed in a number of cells and may represent different phases of resealing. Pinching commenced before the major depolarization; transection occurred $10 \mathrm{sec}$ after laser firing was stopped. Bottom, The cell and electrode are shown in the photograph $15 \mathrm{sec}$ after laser firing. The $\mathrm{HeNe}$ target laser and site of transection are identified by an arrowhead. Objective: Zeiss Ultrafluar $\times 10$ (non-phase); minimum laser focus diameter: $4.5 \mu \mathrm{m}$.
Electrophysiological recordings of membrane potentials reveal a relatively rapid resealing of the lesion. This is demonstrated in Figure 10, which shows a return to normal resting potential within 3 min after a substantial depolarization resulting from a process amputation only $25 \mu \mathrm{m}$ from the cell body and site of recording electrode. Pinching of the neurite was observed during the laser firing; complete transection occurred approximately 10 sec after the laser firing. The neurite was not completely transected at the initiation of the large depolarization. A small depolarization is often seen during the laser firing (Fig. 10, between arrows) and may be an artifact of the lasing. However it could represent $\mathrm{Ca}^{2+}$ release from internal compartments. Repolarization often occurs in distinct phases (i.e., curves $a, b$, and $c$ in Fig. 10) that may represent different stages of cytoskeletal consolidation and membrane repair. Process resealing as reflected by repolarization has been observed in 7 of 16 transection responses.

The description of cell surgery, limited so far to single neurites, also applies to multifiber bundles. These occur frequently in culture and have been used effectively for studies of fiber degeneration (Mire et al., 1970; Bird, 1978; Sole, 1980). Based on observations with the light microscope, we again conclude that the multishot, low energy density method is superior to the single shot approach. This is demonstrated by Figure $11, A$ to $C$, which shows the successive transections of a glial fiber bundle and a cable consisting primarily of neuronal processes. At the site of amputation, the two bundles are separated by $12 \mu \mathrm{m}$. Despite the use of a low power objective (Zeiss Ultrafluar $\times 10$ ), the glial bundle has been transected without overt effects on the neuronal cable. As no shock waves are generated by the multishot method, the neuronal cable did not show any movement during the irradiation of the glial bundle, even though delicate manipulations of the microscope stage revealed lateral drift of the floating neuronal cable. The subsequent irradiation of this cable also revealed no movement until transection, at which time the cut ends drifted slowly apart. Therefore, it appears that the same pinching and gradual transection phases described for single processes occur collectively in fiber bundles. It is important to note that these transections were not accompanied by spiral retractions that are so often associated with mechanical techniques (Bird, 1978; Sole, 1980). However, irregular retractions were seen when excessive energy densities created large shock waves that subjected the fiber bundles to considerable stretching (Fig. 11, $D$ and $E$ ).

\section{Discussion}

Laser transection of cell processes in culture is initially a photobiological event. At energy densities below the single shot damage threshold for nonpigmented cytoplasm, only normal absorption phenomena are involved. Above this threshold, nonlinear or multiphoton absorption causes a variety of physical and chemical changes that may lead to cytoplasmic vaporization in the laser focus (Ready, 1971; Berns, 1974; Hillenkamp, 1980; Higgins et al., 1980). The data presented in this paper deal 

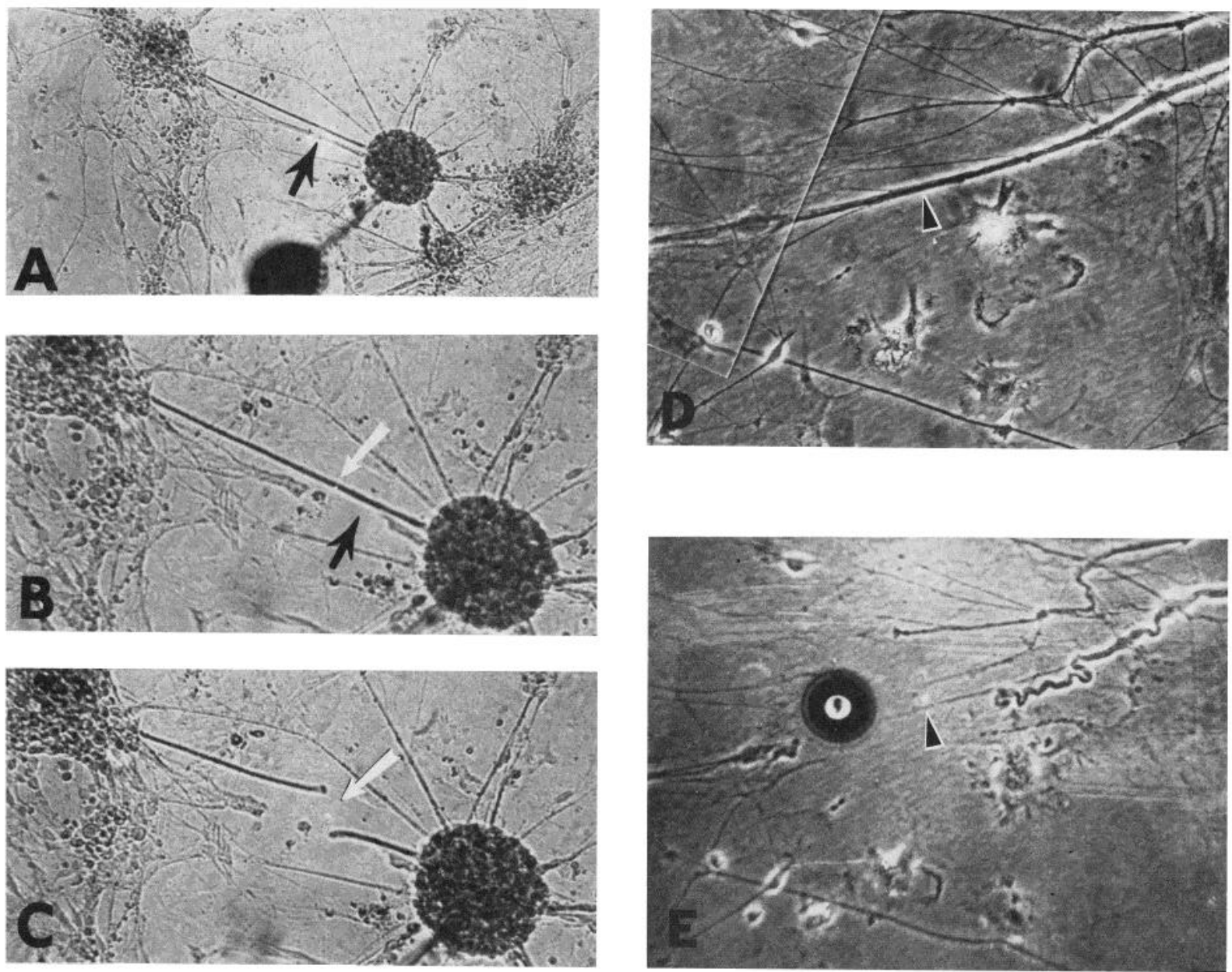

Figure 11. Demonstration of transection of multiple fiber bundles from CNS reaggregates in culture using the multiple shot, low energy technique $(A, B$, and $C)$ and an extreme example of the single shot, shock wave technique $(D$ and $E)$. $A$, HeNe laser beam (black arrow) over glial process prior to transection. Substrate: glass; objective: $\times 10$ ultrafluar (Zeiss). $B$, Twenty seconds after transection of glial bundle $\left(40 \mathrm{~Hz}, 1.7 \mu \mathrm{J} / \mu \mathrm{m}^{2}, 8 \mathrm{sec}\right)$. Note that the large neighboring cable (white arrow) $12 \mu \mathrm{m}$ away was not affected by the laser firing. Magnification $\times 100$. $C$, Seven seconds after transection of multiple fiber bundle $(40 \mathrm{~Hz}, 1.7 \mu \mathrm{J} /$ $\left.\mu \mathrm{m}^{2}, 10 \mathrm{sec}\right)$. Slight swelling of the cut ends was observed. Proximal and distal segments remained relatively straight and did not show evidence of spiral retraction. Magnification $\times 100$. D, Multiple process cable (arrowhead) prior to laser irradiation. Substrate: Falcon polystyrene. Objective: $\times 32$ phase Ultrafluar. $E$, Five seconds after transection using indirect, single shot, shock wave technique $\left(2.8 \mu \mathrm{J} / \mu \mathrm{m}^{2}\right)$. The large bubble resulted from excessive substrate vaporization. Note the spiralling of the retracting segment. Magnification $\times 300$.

with the subthreshold region and the discussion will be limited to normal absorption of photons at $337 \mathrm{~nm}$.

The optical density of cytoplasm at $337 \mathrm{~nm}$ is much less than at $260 \mathrm{~nm}$ or $280 \mathrm{~nm}$ where most effects of UV irradiation have been investigated (Giese, 1964). This relative cytoplasmic insensitivity to radiation at $337 \mathrm{~nm}$ may be an important factor in our achievement of highly localized lesions with laser microbeams. Biologically pertinent molecules that have absorption maxima within 10 $\mathrm{nm}$ of $337 \mathrm{~nm}$ are listed in Table I. These molecules are dispersed throughout the cell and appear in glia as well as in neurons.

We have described morphological and ultrastructural changes in mouse CNS cells and mouse neuroblastoma in response to two laser-induced modes of cell process sectioning: single shot amputations via substrate shock waves and multishot irradiation of cytoplasm resulting in cytoskeletal constriction, collapse, and eventual transection. We have shown that the second technique is the
TABLE I

Molecules with absorption maxima from 327 to $347 \mathrm{~nm}$

\begin{tabular}{lcc}
\hline \multicolumn{1}{c}{ Compound } & $\begin{array}{c}\text { Absorption } \\
\text { Maxima }\end{array}$ & Reference $^{a}$ \\
\hline Benzimidazolylcobamide coenzyme & $n m$ & \\
Coenzyme B $_{12}$ & 340 & 1 \\
NADH & 340 & 1 \\
NADPH & 340 & 2 \\
Kynurenic acid & 339 & 2 \\
Lipoic acid & 344 & 1 \\
Methylcobalamin & 330 & 1 \\
Pyridoxal phosphate & 343 & 1 \\
Pyridoxamine phosphate & 330 & 1 \\
\hline
\end{tabular}

${ }^{a} 1$, Dawson et al. (1965); 2, Lehninger (1975).

superior one because of the gentle, gradual nature of the cytoplasmic reactions and because of the greatly decreased cytoplasmic vacuolization so far observed.

The multishot irradiation data clearly show a loss of 
microtubules in the laser focus within $30 \mathrm{sec}$ after lasing. At later fixation times, there may also be a loss of neurofilaments. Microfilaments have not yet been clearly distinguished. Because of the rapid loss of a major component of the cytoskeleton, a collapse of this structure may be expected. However, the loss of microtubules does not explain the local pinching. The cell process is, at least originally, in osmotic equilibrium with the external medium, and an external pressure cannot be evoked as an explanation for local constriction and the squeezing of cytoplasm out of the target area. Dahl et al. (1982) observed osmotic shrinkage after glucose and oxygen deprivation, but this phenomenon affected the entire cell process and took $2 \mathrm{hr}$ to develop. The substantial depolarizations associated with process transection (Fig. 10) might be expected to lead to a slight swelling (Hill, 1950) rather than to a constriction. Although process constriction usually begins before the depolarization appears, there is no evidence for a major efflux of osmotically active particles in the first few seconds after the start of irradiation.

We speculate that a local contractile event involving actin is triggered by the laser irradiation. It is generally accepted that some actin filaments are anchored in plasma membranes and form a supportive layer below the membrane (Yamada et al., 1971; Durham, 1974; Le Beux and Willemot, 1975). This layer presumably also contributes to the tensile strength of cytoplasm (Allen, 1972 ) and to its ability to withstand local compression (Tilney et al., 1973; Luduena and Wessels, 1973). The phenomenon of endocytosis, which may be related to what we are observing, also appears to be actin dependent (Wolpert and Gingell, 1968) and has been shown to be triggered by a reduction in membrane potential associated with an influx of $\mathrm{Ca}^{2+}$ (Gingell, 1970).

On the basis of this information and our own observations, we propose the following hypothesis for the events leading to cell process transection (Fig. 12). Photons at a wavelength of $337 \mathrm{~nm}$ are absorbed by nicotinamide adenine dinucleotide (NADH) and nicotinamide adenine dinucleotide phosphate (NADPH), which are concentrated in mitochondria. 'The excitation of these molecules leads to the formation of heat and free radicals which force a release of calcium ions from the irradiated mitochondria. A release of calcium from mitochondria in response to laser irradiation in the visible spectrum has been suggested by Olson et al. (1981), who observed swollen mitochondria and vacuolization outside the target area, and by Rattner et al. (1976), who irradiated mitochondria of cardiac muscle cells. At these wavelengths a general heat production is possible. In the UV spectrum, specific absorption at $337 \mathrm{~nm}$ must precede heat production, which could then be caused by nonradiative transitions from excited states to the ground state (Hillenkamp, 1980).

If the local concentration of $\mathrm{Ca}^{2+}$ increases, three events may be initiated: disassembly of microtubules (Dustin, 1978), contraction of actomyosin filaments (Durham, 1974), and the enzymatic breakdown of neurofilaments (Gilbert, 1975; Pant and Gainer, 1980). All three, but primarily the actomyosin contraction, lead to a local pinching of the process. Up to this moment, the

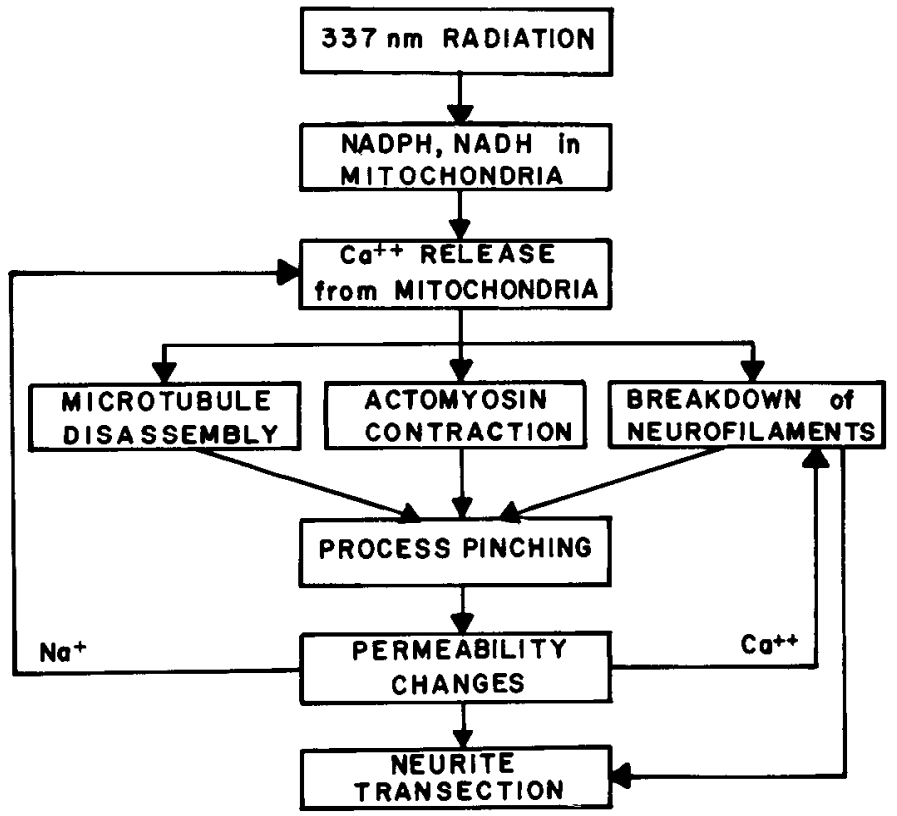

Figure 12. Schematic diagram of proposed sequence of events during multiple shot, low energy laser transection of cell processes. The events listed after mitochondrial $\mathrm{Ca}^{2+}$ release may be true of mechanical transection as well.

situation is reversible. However, at some point the pinching and concomitant membrane stretching result in a serious breakdown of permeability barriers associated with a large influx of $\mathrm{Na}^{+}$and $\mathrm{Ca}^{2+}$. Increased $\mathrm{Na}^{+}$levels are known to accelerate release of $\mathrm{Ca}^{2+}$ from mitochondria (Carafoli and Crompton, 1978). This further increase in intracellular $\mathrm{Ca}^{2+}$ speeds up the breakdown of neurofilaments and leads to a catastrophic collapse of the cytoskeleton. Continued contraction at the periphery of the lesion retracts cytoplasm and membrane and pro-

It is important to note that the description of ultrastructural changes following mechanical transection in culture tally in many respects with our own observations. Swollen mitochondria, vacuoles, lamellar bodies, and swollen endoplasmic reticulum are also seen with the laser method, albeit less frequently with the multishot technique. It must be pointed out, however, that we are looking at a very short time frame after the transection (10 sec to $10 \mathrm{~min}$ ). Most analyses with mechanical transection methods were degeneration oriented and data were generally gathered from $30 \mathrm{~min}$ to days after the lesion (Mire et al., 1970; Bird, 1978). Significantly, none of these studies has mentioned the disappearance of microtubules which is a striking characteristic of our TEM observations. Sole (1980), however, who investigated the effects of transection at $4 \mathrm{~min}$, observed a reduction in the number of microtubules.

Following mechanical transection, several investigators have observed spiral retractions (Shaw and Bray, 1977; Bird, 1978; Sole, 1980) and spillage of cytoplasm from cut ends (Lubinska, 1955; Bird, 1978). We generally do not observe either of these reactions with single processes or process bundles (Fig. 11). This is especially true of the multishot technique where these phenomena have never been observed. This difference may be due to 
mechanical tension and torsion created by the microknife devices. However, the absence of cytoplasmic spillage may be partially the result of as yet undefined cytoplasmic changes in and at the periphery of the laser focus.

All methods of cell surgery, mechanical process transection (Levi and Meyer, 1945; Bird, 1978), cell perforation with microneedles (Levi and Meyer, 1945), and laser microbeam irradiation (Lucas et al., 1982), are associated with cytoplasmic disruptions, the most obvious of which is vacuole formation. The extent of vacuolization is correlated with the degree of membrane disruption: local, limited vacuole appearance resulting from small punctures, and extensive vacuolization that spreads throughout the cytoplasm in 30 to $60 \mathrm{sec}$ resulting from more substantial damage, especially from process stretching (Levi and Meyer, 1945). In extreme cases this stretching may account for the large intermittent vacuoles or "beading" often observed (Levi and Meyer, 1945; Mire et al., 1970). It is interesting to note that a study by Mire et al. (1970) has demonstrated reactions of neuronal cells in vitro to process transections that are similar to those following glucose and $\mathrm{O}_{2}$ deprivation. They have speculated that both situations result in a loss of selective permeability of the cell membrane followed by ion and concomitant water fluxes as well as by loss of soluble, metabolically active molecules. A later study by Dahl et al. (1982) of starved cells came to similar conclusions.

It appears that the initial photobiological events during laser irradiation at $337 \mathrm{~nm}$ produce cytoskeletal damage representative of reactions to physical trauma. We have no evidence to suggest that secondary photobiological events obscure or change the normal cell reactions to injury. Consequently, we are of the opinion that this method of cell surgery can be used to effect physical, experimental lesions with heretofore unprecedented accuracy and reproducibility. Although this method has general applications in cell culture, it is of special significance to research in cellular neurobiology where correlation of morphology and function, response to trauma, regeneration of neurites, transport mechanisms, and behavior of surgically simplified neuronal networks are crucial areas of investigation.

\section{References}

Allen, R. D. (1972) Biophysical aspects of pseudopodium formation and retraction. In The Biology of Amoeba, K. Jeon, ed., pp. 201-247, Academic Press, Inc.., New York.

Berns, M. W. (1974) Biological Microirradiation: Classical and Laser Sources, Prentice-Hall, Inc., Englewood Cliffs, NJ.

Bird, M. M. (1978) Microsurgical transection of small nerve fibre bundles in vitro. Cell Tissue Res. 190: 539-553.

Bowling, D., J. Nicholls, and I. Parnas (1978) Destruction of a single cell in the central nervous system of the leech as a means of analyzing its connections and functional role. J. Physiol. (Lond.) 282: 169-180.

Butz, E. G., and J. D. Cowan (1974) Transient potential in dendritic systems of arbitrary geometry. Biophys. J. 14: 661689.

Carafoli, E., and M. Crompton (1978) The regulation of intracellular calcium by mitochondria. Ann. N. Y. Acad. Sci. 307. 269-284.

Chambers, R., and H. B. Fell (1931) Micro-operation on cells in tissue cultures. Proc. R. Soc. Lond. 109: 380-403.
Cohan, C. S., R. D. Hadley, and S. B. Kater (1982) Zap axotomy: Growth of single axons induced by localized fluorescent dye irradiation. Soc. Neurosci. Abstr. 8: 306.

Dahl, M. A., G. A. Looner, and W. H. Black (1982) Ultrastructure of nonmyelinated neurons during energy deprivation. Acta Neuropathol. 57: 111-120.

Dawson, R. M. C., D. C. Elliot, W. H. Elliot, and E. M. Jones (1969) Data for Biochemical Research, Oxford University Press, New York.

Durham, A. C. H. (1974) A unified theory of the control of actin and myosin in nonmuscle movements. Cell 2: 123-136.

Dustin, P. (1978) Microtubules, Springer-Verlag, Berlin.

Giese, A. C. (1964) Studies on ultraviolet radiation action upon animal cells. In Photophysiology, Action of Mechanisms, and Microorganisms; Photobiochemical Mechanisms, and Bioluminescence, A. C. Giese, ed., Vol. II, pp. 203-246, Academic Press, Inc., New York.

Gilbert, D. S. (1975) Axoplasm chemical composition in $\mathrm{Myxi}$ cola and solubility properties of its structural proteins. J. Physiol. (Lond.) 253: 303-319.

Gingell, D. (1970) Contractile responses at the surface of an amphibian egg. J. Embryol. Exp. Morphol. 23: 583-609.

Gross, G. W. (1979) Simultaneous single unit recording in vitro with a photoetched laser deinsulated gold multimicroelectrode surface. IEEE Trans. Biomed. Eng. 26: 273-279.

Gross, G. W., and J. H. Lucas (1982) Long-term monitoring of spontaneous single unit activity from neuronal monolayer networks cultured on photoetched multielectrode surfaces. J. Electrophysiol. Tech. 9: 47-60.

Gross, G. W., M. L. Higgins, and M. N. Smith (1979) Analysis of the mechanism of neurite transection in culture with pulsed UV laser microbeam irradiation. Soc. Neurosci. Abstr. 5: 755 .

Gross, G. W., A. N. Williams, and J. H. Lucas (1982) Recording of spontaneous activity with photoetched microelectrode surfaces from mouse spinal neurons in culture. J. Neurosci. Methods 5: 13-22.

Higgins, M. L., M. N. Smith, and G. W. Gross (1980) Selective cell destruction and precise neurite transection in neuroblastoma cultures with pulsed ultraviolet laser microbeam irradiation: An analysis of mechanisms and transection reliability with light and scanning electron microscopy. J. Neurosci. Methods 3: 83-99.

Hill, D. K. (1950) The effect of stimulation on the opacity of a crustacean nerve trunk and its relation to fibre diameter. J. Physiol. (Lond.) 111: 283-303.

Hillenkamp, F. (1980) Interaction between laser radiation and biological systems. In Lasers in Biology and Medicine, F. Hillenkamp, R. Pratesi, and C. A. Sacchi, eds., pp. 37-68, Plenum Press, New York.

Horwitz, B. (1981a) An analytical method for investigating transient potentials in neurons with branching dendritic trees. Biophys. .J. 36: 155-192.

Horwitz, B. (1981b) Neuronal plasticity: How changes in dendritic architecture can affect the spread of postsynaptic potentials. Brain Res. 224: 412-418.

Le Beux, Y. J., and J. Willemot (1975) An ultrastructural study of the microfilaments in rat brain by means of E-PTA staining and heavy meromysin labeling. II. The synapses. Cell Tissue Res. 160: 37-68.

Lehninger, A. L. (1975) Biochemistry, Worth Publishers, Inc., New York.

Levi, G., and H. Meyer (1945) Reactive, regressive and regenerative processes of neurons, cultivated in vitro and injured with the micromanipulator. J. Exp. Zool. 99: 141-181.

Lubinska, L. (1956) Outflow from cut ends of nerve fibers. Exp. Cell Res. 10: 40-47.

Lucas, J. H., H. Stewart, M. L. Higgins, and G. W. Gross (1982) UV laser multishot transection of glial and neuronal cell 
processes at low energy densities. Soc. Neurosci. Abstr. 8: 235.

Luduena, M. A., and N. K. Wessels (1973) Cell locomotion, nerve elongation, and microfilaments. Dev. Biol. 30: 427440.

Miller, J. P., and A. T. Selverston (1979) Rapid killing of single neurons by irradiation of intracellularly injected dye. Science 206: 702-704.

Mire, J. J., W. J. Hendelman, and R. P. Bunge (1970) Observation on a transient phase of focal swelling in degenerating unmyelinated nerve fibers. J. Cell Biol. 45: 9-22.

Olson, J. E., W. Schimmerling, G. C. Gundy, and C. A. Tobias (1981) Lascr microirradiation of ccrebcllar neurons in culture: Electrophysiological and morphological effects. Cell Biophys. 3: 349-371.

Pant, H., and H. Gainer (1980) Properties of a calcium-activated protease in squid axoplasm which selectively degrades neurofilament proteins. J. Neurobiol. 11: 1-12.

Parnas, E., and D. Bowling (1977) Killing of single neurons by intracellular injection of proteolytic enzymes. Nature 270: 626-618.

Rall, W., and J. Rinzel (1973) Branch input resistance and steady attenuation for input to one branch of a dendritic neuron model. Biophys. J. 13: 648-688.

Ransom, B. R., E. Neale, M. Menkart, R. N. Bullock, and P. G. Nelson (1977) Mouse spinal cord in cell culture. I. Morphological and intrinsic neuronal electrophysiological prop- erties. J. Neurophysiol. 40: 1132-1150.

Rattner, J. B., M. Lifsics, S. Meredith, and M. W. Berns (1976) Argon laser microirradiation of mitochondria in rat myocardial cells. VI. Correlation of contractility and ultrastructure. J. Mol. Cell. Cardiol. 8: 239-248.

Ready, J. F. (1971) Effects of High Power Laser Radiation, Academic Press, Inc., New York.

Rieske, E., and G. W. Kreutzberg (1978) Neurite regeneration after cell surgery with laser microbeam irradiation. Brain Res. 143: 478-483.

Rieske, E., G. W. Gross, and G. W. Kreutzberg (1977) Laser in der Experimentellen Zellforschung. Laser Elektro-Optik. 2: 44-45.

Shaw, G., and D. Bray (1977) Movement and extension of isolated growth cones. Exp. Cell Res. 104: 55-62.

Sole, G. M. (1980) The effects of microsurgical transection of neurite bundles in vitro before and after exposure to colchicine. J. Anat. 130: 777788 .

Tilney, L. G., S. Hatano, H. Ishikawa, and M. Hooseder (1973) The polymerization of actin: Its role in the generation of the acrosomal process of certain echinoderm sperm. J. Cell Biol. 59: $109-126$.

Wolpert, L., and D. Gingell (1968) Cell surface membrane and amoeboid movement. Symp. Soc. Exp. Biol. 22: 169-198.

Yamada, L. G., B. S. Spooner, and N. K. Wessels (1971) Ultrastructure and function of growth cones and axons of cultured nerve cells. J. Cell Biol. 49: 614-635. 